\title{
LA PROBLEMÁTICA POLÍTICO-EDUCATIVA DE LA INTEGRACIÓN
}

\section{CONSIDERACIONES PARA UNA ACTUALIZACIÓN DEL MENSAJE BOLIVARIANO}

\author{
Adriana Arpini* \\ UNCuyo - CONICET \\ Mendoza - Argentina
}

\section{Resumen:}

Las sucesivas formas en que en la Argentina se encaró la modernización desde la época de la organización nacional hasta nuestros días, muestran un marcado desinterés por los problemas de la integración. Antes bien, tanto las políticas sociales y culturales internas, como las políticas económicas que fijaron la posición de la Argentina en el mercado mundial, favorecieron la desintegración y la exclusión de importantes sectores de la población, en lo interno; y en lo externo fomentaron la rivalidad con los países limítrofes y la tendencia a la desvinculación

* Profesora y Doctora en Filosofía por la Facultad de Filosofía y Letras de la Universidad Nacional de Cuyo, Mendoza, Argentina. Investigadora Independiente de CONICET en las líneas temáticas de la Filosofía Práctica y la Historia de las Ideas Hispanoamericanas. Profesora Titular Efectiva de "Antropología Filosófica" y Profesora Asociada Efectiva de "Ética Social y Profesional" en la Universidad Nacional de Cuyo. Mendoza, Argentina. Profesora de postgrado. Autora y compiladora de libros: América Latina y la moral de nuestro tiempo (Mendoza, EDIUNC, 1997), Razón práctica y discurso social latinoamericano (Buenos Aires, Biblos, 2000). Filosofía, narración, educación (Mendoza, Qellqasqa, 2002), Eugenio María de Hostos, un hacedor de libertad (Mendoza, EDIUNC, 2002). Autora de artículos en revistas especializadas de su país y extranjeras. Directora de proyectos de investigación de la SECyTUNC y de CONICET (Argentina). 
con otros países de América Latina. Todo ello dificultó la puesta en práctica de proyectos de integración latinoamericana y la formación de bloques económicos regionales. Las políticas educativas estuvieron a tono con esta orientación general, fomentando a través del curriculum y de los rituales instalados en las prácticas educativas cierta comprensión de lo nacional presentada como excluyente de otras posiciones abiertas a la integración. En esa línea lo nacional se opone a lo regional, lo "propio" constituye una barrera para visualizar lo "común".

Sin embargo, desde época temprana en la formación de nuestra nacionalidad, se plasmaron y defendieron proyectos de integración en la línea del ideal bolivariano de unidad continental. En este sentido resulta valioso recuperar los planteos de Bernardo de Monteagudo, Juan Bautista Alberdi, Manuel Ugarte, José Ingenieros, Julio Ricardo Barcos entre otros. Apoyándonos en sus propuestas y actualizándolas, sería posible avanzar en formulaciones superadoras y críticas de las contradicciones actuales.

Existe una opinión, ampliamente aceptada, según la cual se da entre los argentinos, y en particular entre los intelectuales, cierta predisposición para preferir y asimilar la producción cultural procedente de los países europeos e, incluso de los Estados Unidos, antes que la procedente de otros países de América Latina. Esta preferencia se explicaría apelando a razones históricas, económicas, geográficas y demográficas. Efectivamente, desde los tiempos de la colonia, en la Cuenca del Plata, las características del territorio y la escasez de riqueza metalífera habrían dado origen a una sociedad con ciertos elementos propios del mundo moderno como el trabajo personal y el comercio como base de la riqueza-, a diferencia de lo sucedido en otras regiones de la América mestiza. A ello se sumaría, posteriormente, las políticas migratorias que darían lugar al surgimiento de una clase media numerosa. 
Otra opinión muy difundida marca una diferencia entre la actitud típica del "porteño" -habitante del litoral argentino- y la de los hombres del interior. Esta fractura se explicaría en función de la relativa prosperidad alcanzada en la región del litoral portuario, entre fines del siglo XIX y principios del XX, en comparación con otros países latinoamericanos y con el resto del propio país.

Tales opiniones ponen de manifiesto el complejo problema de la integración, pues, por una parte se advierten los conflictos que dividen a diversos sectores de la vida nacional, expresados discursivamente a través de categorías tales como: interior / litoral, campo / ciudad, obrero / patrón, indio / criollo / inmigrante, barbarie / civilización. Por otra parte, evidencian el desinterés por definir políticas de desarrollo nacional en el marco de un proyecto de colaboración y defensa mutua con las naciones hermanas de América Latina. Hecho, éste, cuya realización fue considerada por nuestros libertadores como un paso necesario para asegurar la independencia.

En efecto, quienes, desde la época de la organización nacional hasta nuestros días, han asumido la responsabilidad de tomar las decisiones que pusieran a la Argentina en el camino de la modernización, han mostrado un marcado desinterés por los problemas de la integración. Antes bien, tanto las políticas sociales y culturales, como las políticas económicas que fijaron la posición de la Argentina en el mercado mundial en tanto proveedora de materias primas, favorecieron, en lo interno, la desintegración y la exclusión de importantes sectores de la población y, en lo externo, fomentaron la rivalidad con los países limítrofes y la tendencia a la desvinculación con otros países de América Latina. 
Todo ello dificultó la puesta en práctica de proyectos de integración latinoamericana y trabó la formación de bloques económicos regionales. Las políticas educativas estuvieron a tono con esa orientación general, fomentando a través del curriculum y de los rituales instalados en las prácticas educativas cierta comprensión de lo nacional presentada como excluyente de otras posiciones abiertas a la integración. En esta línea de pensamiento lo nacional -identificado con los intereses de los sectores sociales dominantes- se opone a lo regional, lo "propio" constituye una barrera para visualizar lo "común" por encima de las diferencias.

El discurso pedagógico liberal de la generación de 1837 no dejó lugar para alianzas con los sectores populares y menos aún con los nativos. Éstos, caracterizados por Sarmiento como hordas indisciplinadas e incapaces, fueron expulsados de la categoría de "pueblo" e ignorados como sujetos de la educación. Por otra parte, la categoría abstracta de "población", utilizada para designar a los sectores populares, sirvió para uniformar las múltiples determinaciones de los sujetos sociales concretos, al tiempo que se desarticuló su discurso y se los consideró como bárbaros a los que había que convertir en ciudadanos. El "pueblo" estuvo presente sólo en su condición pasiva de educando que debía ser formado. "La escuela era la continuación de la guerra por otros medios ... y el educador un civilizador. ...[El] lugar de la palabra del educando había quedado vacío y sobre él se derramaba un discurso educador" (Puiggrós, A., 1990, 87 - 88).

En los mismos términos fue asumida, poco tiempo después, la problemática de los inmigrantes, los cuales disponían de una instrucción inferior a la esperada y pronto fueron considerados como factor de perturbación. El significante "barbarie" se cargó de nuevos significados y se lo utilizó para designar a los inmigrantes, campesinos y sectores urbanos subalternos. Se impregnó de connotaciones raciales y penetró en el discurso pedagógico generando circuitos desiguales de escolarización, producción y distribución de la cultura, que perduran y se 
recrudecen en nuestros días. Según el discurso pedagógico positivista, la escuela fue la encargada de corregir los hábitos desviados, trasmitir conocimientos e imprimir rituales disciplinarios de acuerdo con el lugar subordinado de los inmigrantes dentro de las relaciones sociales, políticas y pedagógicas. La clase dirigente argentina, que reivindicaba su propio origen europeo, marginó al inmigrante, negó al indígena y desconoció los vínculos culturales con el resto de América Latina

En síntesis, la problemática de la integración presentó dos dimensiones: una interna, referida a los modos de incorporación de los diversos sectores sociales a la vida nacional; otra continental, referida a la forma en que se entablaron lazos de cooperación e intercambio con los países de América Latina. En ambos casos las políticas educativas nacionales jugaron un papel decisivo, generando un sistema de educación pública desconectado de la sociedad civil, centralizado, verticalista y disciplinario; cuyo discurso expresó a través de las categorías "barbarie" y "civilización", un juego de valoraciones negativas y positivas, que niveló las diferencias internas por la imposición de la civilización y el desconocimiento del otro. Al mismo tiempo fue poco permeable a la idea de estrechar vínculos culturales, políticos y sociales con los países de América Latina. Antes bien, la defensa del territorio nacional fue utilizada en más de una ocasión como pretexto para fomentar la animosidad respecto de los países limítrofes.

Pero hubieron otros discursos que intentaron rescatar la idiosincrasia del pueblo y su capacidad creadora. Tal es el caso de Carlos Norberto Vergara, quien bajo el lema "No hay más educación que la educación de la libertad, en la libertad y para la libertad" (Vergara, C., 1916, 241), invirtió el modelo sarmientino de la educación pública, confiando en la capacidad del pueblo para ser su propio maestro, gobernar y dirigir su propia educación. Por otra parte, el discurso del movimiento reformista reelaboró el mensaje bolivariano de identificación latinoamericanista. Frente al peligro de los imperialismos, este discurso defendió la 
integridad territorial regional, la autonomía de las decisiones en materia económica y política, el fortalecimiento de la cultura propia y la construcción de un destino común para los países de América Latina en el marco de la historia mundial.

Estos ejemplos ponen de manifiesto las fisuras del discurso hegemónico, abren la posibilidad de rastrear otros discursos en los que la problemática de la integración -en la dimensión de lo nacional así como en relación con la América Latina- fue planteada en términos diferentes y permiten detectar en ellos las alternativas transformadoras capaces de vigorizar nuestro propio discurso. En este sentido ejercemos el derecho a deconstruir y reconstruir nuestra memoria histórica, redefinir y proponer categorías para la comprensión del presente y la proyección del futuro; en síntesis, crear y recrear el discurso sobre nuestra identidad.

En efecto, la problemática de la integración latinoamericana estuvo presente en pensadores y hombres de acción desde los albores de nuestra vida independiente. Así, Bernardo de Monteagudo escribió en 1824 -en momentos en que Bolívar convocaba el Congreso de Panamá- un "Ensayo sobre la necesidad de una federación general entre los estados hispanoamericanos". Los lineamientos políticos de dicha federación se enderezaban a consolidar los derechos de los pueblos y garantizar la independencia y la paz, estrechando las relaciones entre los americanos "para que aprendan a identificar sus intereses y formar a la letra una sola familia" (Monteagudo, B., 1979).

En 1845, dos años antes de que se reuniera el Congreso Americano de Lima (1847-48), el mismo Alberdi escribió una "Memoria sobre la conveniencia y objeto de un Congreso General Americano", el cual debía concentrar sus esfuerzos en la causa de la población, la riqueza y la civilización de las repúblicas americanas de origen español, considerando "frívolas las pretensiones de hacer familia común 
con los ingleses republicanos de Norteamérica" (Alberdi, J.B., 1979). Idéntico espíritu impulsó la participación de Gregorio Las Heras en el movimiento intelectual y político que fundó en Valparaíso, en 1862, la Unión Americana. Cabe aclarar que los términos "americano" y "americanismo" fueron utilizados hasta avanzado en siglo XIX para designar al conjunto de las naciones americanas recientemente emancipadas de España, con un fuerte sentido defensivo frente a la amenaza de una posible revancha europea. Sin embargo, desde mediados de ese siglo, se hizo evidente la necesidad de reformular el americanismo, a fin de diferenciar las repúblicas latinas de América de los Estados Unidos de Norte América y alertar acerca del peligro de una política agresiva de expansión sostenida en una interpretación "positiva" de la Doctrina Monroe (Ardao, A., 1993, 19; Arpini, A., 1993, 218).

La expansión norteamericana, desembozada a partir de la expulsión de España de sus últimas posesiones en el Caribe, suscitó diversas reacciones en toda América Latina que se tradujeron en términos de antiimperialismo y afirmación de la propia nacionalidad. Tal es el caso de Manuel Ugarte, quien antepuso el interés supremo de la patria que "en su concreción directa es la Argentina, y en su ampliación virtual es la América hispana". Ello no implicó cerrar toda posibilidad de diálogo con la América del Norte; se trataba más bien de encontrar caminos superadores que permitan "relacionarnos con ellos en los desarrollos de la vida futura; pero ... sobre una plataforma de equidad". "Autonomía" y "resistencia" son las ideas que articulan el discurso de Ugarte. La autonomía es entendida en el marco de un proyecto de integración hispanoamericana para el que convocó a "trabajar a favor de un Continente moralmente unido hasta rehacer por lo menos diplomáticamente el conjunto homogéneo que soñaron los iniciadores de la independencia, reconquistar con la ayuda de la unión el respeto y la seguridad de nuestros territorios, y hacer a cada república más fuerte y más próspera dentro de una coordinación superior, garantía suprema de las autonomías regionales" (Ugarte, M., 1962, 22). La resistencia, en cambio, estuvo vinculada al llamado de atención sobre los peligros inmediatos, en particular sobre el "peligro yanqui" que 
"no implica una agresión inmediata, sino un trabajo paulatino de invasión comercial y moral que se iría acreciendo con las conquistas sucesivas y que irradiará, cada vez con mayor intensidad, desde la frontera en marcha hacia nosotros" (Ugarte, M., 1978, 66).

La unión solidaria de los pueblos latinoamericanos fue entendida como una forma de resistencia por Ugarte, pero señaló, además, la necesidad de volver la mirada sobre nosotros mismos para descubrir la "visión estrecha y ensimismada", la "interpretación regional y mutilada" de nuestra propia historia que imparte la enseñanza escolar, alentada por quienes "creen aldeanamente en la buena fe de la política internacional y se ponen a la zaga del resbaloso panamericanismo" (Ibidem).

El término "panamericanismo" designa una suerte de panismo geográfico con intenciones políticas, que se inicia con la creación de la Oficina Comercial de las Repúblicas Americanas el 14 de abril de 1890, en la órbita del gobierno de Washington. En oposición a la puesta en práctica de este panamericanismo, el mexicano José Vasconcelos impulsó la creación de una Unión Latinoamericana. Con este propósito llegó a la Argentina en 1922. José Ingenieros en su discurso de homenaje al mexicano, alertó contra la "trayectoria alarmante" de la política imperialista norteamericana, denunció los engaños con que la "diplomacia del dólar" captura la conciencia y la voluntad de los estadistas y señaló la necesidad de "resistir" activando "las fuerzas morales" en el sentido de una progresiva integración de los pueblos latinoamericanos, hasta la formación de una confederación política y económica, tarea que Ingenieros entendió como la "misión de la juventud latinoamericana" (Ingenieros, J., 1979, 10). 
En esta misma línea de pensamiento, Julio Ricardo Barcos, escritor y maestro argentino -cuyo singular proyecto ha sido rescatado por Arturo Roig (1998, 137)-, propuso llevar adelante acciones concretas, mediante la creación de una Universidad de la Cultura Americana. Institución de alcance continental, supranacional, cuyo objetivo fundamental sería el conocimiento de nuestra realidad y la realización de "una grande y fuerte hermandad intelectual americana, capaz de velar tanto por la libertad de la cultura, cuanto por la existencia económica y política de esta gran familia de naciones, entroncadas al mismo árbol glorioso de la raza hispana". Propuso la educación técnica como defensa contra el imperialismo, entendiendo que la libertad de los pueblos se consigue con las fuerzas creadoras del trabajo, "desde abrir un suco hasta crear un sistema filosófico". Sin embargo se manifestó en contra de las formas de saber académico que practicaba la "ciencia europea" y rechazó la concepción estrecha de universidad cuyas funciones estaban limitadas a la producción de profesionales y dirigentes. La Universidad de la Cultura se proponía levantar los valores de la intelectualidad libre, convocando a los "ciudadanos de la cultura" de toda América. Una actividad central de dicha universidad sería la creación de una Editorial para la Cultura Americana "encargada de difundir las mejores obras de los mejores autores de todo el Continente"; asimismo, para las actividades de extensión propuso apelar a los recursos tecnológicos más avanzados de la época, la radiocomunicación y la cinematografía (Cfr. Roig, A., 1998).

En suma, junto al discurso oficial, frente a él, se ha desarrollado otro discurso que, con diversas acentuaciones, ha tenido presencia continuada y ha canalizado tanto el reconocimiento de las diversas formas de identificación cultural, como la voluntad de integración en torno a un proyecto común latinoamericano. Dicho proyecto constituye una reformulación del ideal bolivariano en torno a los siguientes puntos: 
- Reconocimiento del potencial creador de los distintos sectores sociales y expresiones culturales.

- Defensa de la integridad territorial frente a los imperialismos.

- Autonomía en la definición de los intereses propios y en las decisiones políticas y económicas.

- Resistencia frente a las formas encubiertas de invasión comercial y moral.

- Fortalecimiento de las propias culturas y amplitud para la interpretación de lo diverso.

- Capacidad para afirmar por encima de las diferencias, pero sin desconocerlas, la voluntad de construir y participar en un proyecto común de unidad latinoamericana.

¿Cómo podemos nosotros aportar a la realización de este proyecto común? Una posibilidad consiste en hacer uso inteligente de las instituciones y los instrumentos existentes. En el terreno de la educación, por ejemplo, existe el Compromiso de Gramado que proporciona el marco de referencia para definición del plan de acción en el sector educativo del Mercosur. Dicho Compromiso establece como su más alta finalidad "Contribuir a los objetivos del Mercosur conformando un espacio educativo común, estimulando la formación de la conciencia ciudadana para la integración, la movilidad y los intercambios con el objeto de lograr una educación de calidad para todos, con atención especial a los sectores más vulnerables en un proceso de desarrollo con justicia social y respeto a la diversidad cultural de los pueblos de la región". Hasta el presente las acciones concretadas son predominantemente de carácter formal o estructural como la firma de protocolos de integración educativa y reconocimiento de certificados o reválida de diplomas, la constitución y puesta en marcha de un sistema de información y comunicación, diseño e implementación de políticas dirigidas a la enseñanza de la 
historia y la geografía, diseño y ejecución de programas de posgrado regionales, entre otras.

¿Podría pensarse en dotar a esa estructura formal de contenidos inspirados en los lineamientos de la Universidad de la Cultura Americana, tal como la propuso Julio Barcos, con su editorial para la difusión de las mejores obras de nuestra cultura y apelando a los medios más eficaces que la tecnología pone hoy a nuestro alcance? ¿Será posible que el ideal de unidad latinoamericana de inspiración bolivariana movilice la conciencia crítica y oriente las definiciones en materia de políticas educativas y culturales? ¿Será el siglo XXI el tiempo de la integración y el reconocimiento mutuo?

\section{Bibliografía:}

- Alberdi, Juan Bautista, (1979), "Memoria sobre la conveniencia de un Congreso General Americano", en: Latinoamérica. Cuadernos de cultura latinoamericana. No 42, México, UNAM.

- Ardao, Arturo, (1993), América Latina y la latinidad. México, Universidad Nacional Autónoma de México (Colección 500 años después).

- Arpini, Adriana, (1993), "El latinoamericanismo de los argentinos", en: Roig, Arturo, (compilador), La Argentina del '80 al '80. Balance social y cultural de un siglo. México, Universidad Nacional Autónoma de México.

- Compromiso de Gramado, http://www.ufpel.tche.br/mercosul/educar.htm

- Da Silva, Carlos Alfredo - Zanin, Gabriela, (2001), "Mercosur - Cono Sur Latinoamericano. Entre la crisis y la globalización”, en: Rubinelli, M. L., Sujetos 
sociales y educación en la Argentina hoy. San Salvador de Jujuy, Universidad Nacional de Jujuy. (137 - 152).

- Ingenieros, José, (1979), “José Vasconcelos”, en: Latinoamérica. Cuadernos de cultura latinoamericana. No 74, México, UNAM.

- Monteagudo, Bernardo, (1979), "Ensayo sobre la necesidad de una federación general entre los estados hispanoamericanos", en: Latinoamérica. Cuadernos de cultura latinoamericana. $\mathrm{N}^{\circ} 40$, México, UNAM.

- Puiggrós, Adriana - José, Susana - Balduzzi, (1988), Juan, Hacia una pedagogía de la imaginación para América Latina. Buenos Aires, Contrapunto.

- Puiggrós, Adriana, (1990), Sujetos, disciplina y curriculum en los orígenes del sistema educativo argentino. Buenos Aires, Galerna.

- Roig, Arturo, (1998), La universidad hacia la democracia. Bases doctrinarias e históricas para la construcción de una pedagogía participativa. Mendoza, EDIUNC.

- Rubinelli, María Luisa (compiladora), (2001), Sujetos sociales y educación en la Argentina hoy. San Salvador de Jujuy, Universidad Nacional de Jujuy.

- Ugarte, Manuel, (1962), El destino de un Continente. Buenos Aires, Ediciones de la Patria Grande. (El texto data de 1923).

- Ugarte, Manuel, (1978), "El peligro yanqui" (1901), en: La nación latinoamericana. Compilación, prólogo y notas de Norberto Galasso, Caracas, Biblioteca Ayacucho.

- Vergara, Carlos Norberto, (1916), Filosofía de la educación. Buenos Aires, Compañía Sudamericana de billetes de banco. 